\title{
A Comparative Study on Social Maturity of Adolescent Students Undergoing NCC Training and Without NCC Training
}

ISSN: 2311-8636 (Print) ISSN: 2312-2021 (Online)

Licensed:

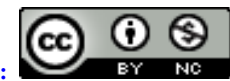

\section{Monoranjan Bhowmik ${ }^{1 *}$, Niranjan Maity ${ }^{2}$}

${ }^{1}$ Assistant Professor, Vidyasagar Teachers' Training College, Paschim Medinipur, West-Bengal, INDIA

${ }^{2}$ Assistant Professor, Ratulia Secondary Teachers Training Institute, Purba Medinipur, West-Bengal, INDIA

Source of Support: Nil

No Conflict of Interest: Declared

${ }^{*}$ Email for correspondence:

mbvttc@gmail.com

\section{ABSTRACT}

The present study focuses on social maturity of adolescent students undergoing NCC (National Cadet Corps) training and without NCC training .The sample consists of 124 school students of Purba Medinipur, District of West Bengal in India. The researchers has developed the social maturity scale and standardized it to apply towards subjects. The researchers analyse the data using statistical technique $t$ - test using the software SPSS. The major finding of the study is that, the adolescent students who got the NCC training achieve more social maturity than the students without NCC training.

Keywords: Social maturity, Adolescent, National Cadet Corps (NCC)

\section{INTRODUCTION}

We are living in the first step of $21^{\text {st }}$ century having wonderful vision and mission. We want to build an India which is knowledge based and value based society guiding the others Nations of the World. We want to make a development of India on out of developing. It is possible only by improving the manpower of our country and no doubt the roles of education in this direction are inevitable. Education to be meaningful has to inculcate the proper values of "live and late live". The United Nations Educational, Scientific and Cultural Organization (UNESCO) has rightly focused on four pillar of education. Out of which the most important pillar is learning to live together. So our education system today needs to focus on creating a cohesive society i.e. a society where believes in mutual trust, tolerance, fellow feeling. Man is the social animal he lives in the society grows in society and died in the society. Social isolation is the figment of imagination. During the outset of life he is helpless and dependent physically socially emotionally. As he grows he learns to develop the skill of adjustment with environment with the help of interaction and exposure it provides the child new learning experiences to face the challenges of life .Out of these challenges, the challenges of adapting with social setting is most important for complete personality development in one hand and social maturity on the other. Children are by definition socially immature and nobody wants 
them to stay way as adults. In fact, a great deal of difficulty involved in being a good parent can be expressed simply as the struggle to figure out what are the best method to use, what are the proper decision to make to help children to find their way to become mature adults.

Social immaturity in adolescent is both a social and personal problem for effected individual; their family's social immaturity either plays as important role in maintaining multiple mental disorders or in fact what defines those disorders. This is particularly true of the dramatic erratic personality disorders including Narcissism, Borderline, Histrionic probably antisocial personality disorder. Social immaturity is also quite frequently associated with long term Alcoholism or drug addiction, which began in adolescence.

\section{OBjectives OF The Study}

Objectives of this study

- To know the social maturity of adolescent students.

- To assess the social maturity of adolescent students of undergoing NCC training.

- To study the social maturity of adolescent students without NCC training.

- To distinguish the level of social maturity between the adolescent students undergoing NCC training and the adolescent student without NCC training.

- To measure the social maturity among the adolescent boys students undergoing NCC training.

- To ascertain the level of social maturity of adolescent girls students undergoing NCC training.

- To assess the social maturity of adolescent boys students without NCC training.

- To study the social Maturity of adolescent girls students without NCC training.

\section{HYPOTHESIS}

The hypothesis of this study are-

$\mathrm{H}_{01}$ There is no significant difference between the adolescent students undergoing NCC training and the adolescent students without NCC training with reference to social maturity.

Ho2: There is no significant difference between adolescent boys' students and the adolescent girls students regarding the social maturity.

$\mathrm{H}_{03}$ : There is no significant difference between adolescent boys' students undergoing NCC training and the adolescent boys' students without NCC training in respect to social maturity.

Ho4: There is no significant difference between adolescent boys' students without NCC training and adolescent girls' students without NCC training with the reference to social maturity.

Ho5: There is no significance difference between adolescent boys' student undergoing NCC training and the adolescent boy students without NCC training regarding social maturity.

Ho6: There is no significant difference between adolescent girls' student undergoing NCC training and the adolescent girls' students without NCC training with reference to social maturity. 


\section{Methodology}

The researcher used the survey type method to conduct this study.

\section{Sample and Sampling Procedure}

The sample of this study comprised total 124 adolescent students, 62 students from undergoing NCC training (boys 31 and girls 31) and 62 without NCC training students (boys 31 and girls 31) from secondary school from Purba Medinipur District of West Bengal, India. The investigator has used the stratified purposive sampling method.

\section{Tools Used}

The aim of this study was to investigate students' social maturation in the undergoing NCC training and without NCC training for reached up to the objectives. The researchers used adapted questionnaire (transformed into Bengali Version) developed by the Vineland Social Maturity Scale (VSMS) was originally derived by E. A. Doll in 1935 and since then this test has used in many parts in the world .The first attempt to adopted this scale in Indian Culture condition was done by Dr. A.J. MALIN, Nagpur, with the Converting in to regional language and the researcher made if in Standardized from. It is "Vineland Social Maturity Scale" (VSMS).

\section{Statistical Techniques Applied}

The researchers used the inferential statistics by SPSS such as $t$ - test was used for interpretation of the data. In this study for analysis of collected data quantitatively; the researchers used the descriptive statistics and inferential statistics.

\section{ANALYSIS AND INTERPRETATION}

$\mathrm{H}_{01}$ : There does not exist any significant difference between the adolescent students undergoing NCC training and adolescent students without NCC training with reference to social maturity.

Table 1: $\mathrm{t}$-values of social maturity of NCC training and without NCC training students

\begin{tabular}{|l|l|l|l|l|l|l|}
\hline Sl .no. & Category & $\mathrm{N}$ & Mean & SEm & $\mathrm{t}$ & $\mathrm{p}$-value \\
\hline 1 & NCC Training & 62 & 59.09 & 2.13 & 2.41 & 0.001 \\
\cline { 1 - 3 } 2 & Without NCC Training & 62 & 53.95 & & & \\
\hline \multicolumn{7}{|c|}{$\mathrm{P}<0.05$} \\
\hline
\end{tabular}

From the above Table 1 the null hypothesis is rejected, that is there is significant between the adolescent students undergoing NCC training and the adolescent students without NCC training, regarding the social maturity.

$\mathrm{H}_{02}$ : There is no significant difference between adolescent boys' students and the adolescent girls students regarding to social maturity

Table 2: t-value of Social maturity between the adolescent boys' students and adolescent girls' students

\begin{tabular}{|l|l|l|l|l|l|l|}
\hline Sl. No & Category & $\mathrm{N}$ & Mean & SEm & $\mathrm{t}$ & $\mathrm{p}$-value \\
\hline 1 & Boys & 62 & 57.13 & 2.17 & 0.56 & 0.062 \\
\cline { 1 - 3 } 2 & Girls & 62 & 55.92 & & & \\
\hline \multicolumn{7}{|c|}{$\mathrm{P}>0.05$} \\
\hline
\end{tabular}


From the Table 2 the null hypothesis is accepted, it says that there is no significant difference between the adolescent boys' students and the adolescent girls' students, regarding the social maturity.

$\mathrm{H}_{03}$ : There is no significant difference between adolescent boys' students undergoing NCC training and the adolescent boys' students without NCC training in respect to social maturity.

Table 3: $\mathrm{t}$ - value of social maturity between adolescent boys' student and adolescent girls' students with NCC training

\begin{tabular}{|l|l|l|l|l|l|l|}
\hline Sl.No & Category & $\mathrm{N}$ & Mean & SEm & $\mathrm{t}$ & $\mathrm{p}$-value \\
\hline 1 & NCC Boys & 31 & 60.16 & 3.34 & 0.64 & 0.012 \\
\hline 2 & NCC Girls & 31 & 58.03 & & & \\
\hline \multicolumn{8}{|c|}{$\mathrm{P}<0.05$} \\
\hline
\end{tabular}

The above Table 3 shows that null hypothesis is rejected, there is significant difference between the adolescent boys' students undergoing NCC training and the adolescent girls' students with NCC training regarding the social maturity.

$\mathrm{H}_{04}$ : There is no significant difference between the adolescent boys' students without NCC training and the adolescent girls' students without NCC training, with the reference to social maturity.

Table 4: $\mathrm{T}$ - values of social maturity of adolescent boys students and adolescent girls student without NCC training

\begin{tabular}{|l|l|l|l|l|l|l|}
\hline Sl. No & Category & $\mathrm{N}$ & Mean & SEm & $\mathrm{t}$ & $\mathrm{p}$-value \\
\cline { 1 - 4 } 1 & Without NCC Boys & 31 & 54.09 & 2.78 & 0.10 & 0.057 \\
\cline { 1 - 3 } 2 & Without NCC Girls & 31 & 53.81 & & & \\
\hline \multicolumn{7}{|c|}{$\mathrm{P}>0.05$} \\
\hline
\end{tabular}

Above Table 4 the null hypothesis is accepted, it says there is no significant difference between the adolescent boy students without NCC training and the adolescent girls' student without NCC training regarding the social maturity.

$\mathrm{H}_{\mathrm{0}}$ : There exist no significant difference between adolescent boys' students undergoing NCC training and the adolescent boys' students without NCC training regarding to social maturity.

Table 5: t-values of social maturity adolescent boys' student undergoing NCC and adolescent boy student without NCC training

\begin{tabular}{|l|l|l|l|l|l|l|}
\hline Sl.No & Category & $\mathrm{N}$ & Mean & SEm & $\mathrm{t}$ & $\mathrm{p}$-value \\
\cline { 1 - 5 } 1 & Boys with NCC & 31 & 60.16 & 3.20 & 1.90 & 0.001 \\
\cline { 1 - 4 } & Boys without NCC & 31 & 54.09 & & & \\
\hline \multicolumn{7}{|c|}{$\mathrm{P}<0.05$} \\
\hline
\end{tabular}

From Table 5 the null hypothesis is rejected, it says that there is significant difference between the adolescent boys' students undergoing NCC training and the adolescent boys' students without NCC training with reference the social maturity. $\backslash$

$\mathrm{H}_{\mathrm{o} 6}$ : There does not exist any significant difference between adolescent girls' student undergoing NCC training and the adolescent girls' student without NCC training with reference to social maturity. 
Table 6: $\mathrm{t}$ - values of social maturity of adolescent girls students undergoing NCC and adolescent girls' students without NCC training

\begin{tabular}{|l|l|l|l|l|l|l|}
\hline Sl.no & Category & $\mathrm{N}$ & Mean & SEm & $\mathrm{t}$ & $\mathrm{p}$-value \\
\hline 1 & Girls With NCC & 31 & 58.03 & 2.96 & 1.43 & 0.002 \\
\cline { 1 - 3 } 2 & Girls without NCC & 31 & 53.81 & & & \\
\hline \multicolumn{7}{|c|}{$\mathrm{P}<0.05$} \\
\hline
\end{tabular}

From Table 6 the null hypothesis is rejected, it says that there is significant difference between the adolescent girls' students undergoing NCC training and the adolescent girls' students without NCC training, with reference the social maturity.

\section{FINDING OF THE STUDY}

After the critical analysis and verification of the data, hypothesis were tested and results were found among the adolescent students undergoing NCC training and the adolescent students without NCC training by considering their gender perspective and especially social maturity.

In this study investigators found that the level of social maturity of adolescent student undergoing NCC training and the student without NCC training is different. From the above study it is found that the adolescent students undergoing NCC training are more socially mature than the adolescent students without NCC training.

This study also showed that a significant difference was found among the adolescence boys students undergoing NCC training and the adolescent boys without NCC training. So, researchers told that the NCC training is the determinant factor and it helps the adolescent students to become socially mature.

\section{CONCLUSION}

Based on the finding of $t$ ratio there exist a significant difference level of social maturity between the adolescent students undergoing NCC training and the students without NCC training. It appears that NCC training helps the adolescent students to develop quality of character, courage, comradeship, leadership, spirit and the ideals of self service. On the other hand the adolescent students without NCC training are behind of such social psychological stimulants, these results on their lower level of social maturity. From the above discussion the researcher suggest that the adolescent students without NCC training were given or provided to them such kinds of social psychology stimulants like the students undergoing NCC training they will be able to show equal level of social maturity.

\section{REFERENCE}

Chauhan S.S. (2004): Advance Educational Psychology, Vikas publication pvt. Ltd, New Delhi.

Delors, Jacques et al. 1996. Learning: The Treasure Within. Paris: UNESCO

Doll, E.A (1953). The measurement of social competence: a manual for the Vineland social maturity scale: Educational Test Bureau educational Publishers.

Fraure, Edgar et al. 1972. Learning To Be: The World of Education Today and Tomorrow. Paris: UNESCO

IBE (International Bureau for Education) and UNESCO Bangkok. 2001. Capacity Building for Curriculum Specialists in, East Asia and South-East Asia. Geneva: IBE

IBE.1999. INNOVATION Newsletter. 
Kaplan E Harriet, Altishe Moses: Comparison of rating by Mother and Teacher on preschool children using V.S.M.S. Online library, Willey .com

Mangal S.K. (2009): Essential of educational Psychology P.H.I. Pvt. Ltd, New Delhi.

Panda K.P. (2005): Fundamental of Educational Research, Viswavidalaya Prakasan, Varanasi.

Raggio, D. J, and Massingale. (1990) .Comparability of the Vineland social Maturity scale and vinel and Adaptive Behaviour Scale - Survey form with infants evaluated for developmental: Perceptual and Motor skill Vol 71 (2) Oct 1990, pp 415-418.

Raggio, D. J, and Massingale. (1993) .Comparability of the Vineland social Maturity scale and vinel and Adaptive Behaviour Scale - Survey form with infants evaluated for developmental: Perceptual and Motor skill Vol 77 (1) Dec 1993, pp 931-937.

Roszkowski, M.J. (1980) .Conccurrent validity of the adaptive Behaviour Scale as assessed by the vinel and Social maturity Scale: American Journal of Mental Deficiency Vol 85 (1) Jul 1980, pp 86-89.

Rychen, D.S. and A. Tiana, 2004, Developing Key Competencies in Education: Some Lessons from International and National Experience, Geneva: UNESCO-IBE, Studies in Comparative Education.

Safia, Dr. Bhatia R.N. (2005): Modern theory and principal of Education, Dhanpat raj publication, New Delhi.

Sharma R.A. (2002): Advance statistics in education and psychology, surya publication, Meerut.

UNESCO. 2004. EFA Global Monitoring Report. Paris: UNESCO

UNESCO.2004. EFA Global Monitoring Report 2005. Paris. UNESCO Press.

Publish Online and Print Version Both

Online ISSN: 2312-2021

Google Scholar: https://goo.gl/eozEWi 